\title{
TEMBANG MACAPAT CENGKOK MERDI LAMBANG (MERSUDI LARAS LAGUNING TEMBANG)
}

\author{
Darsono \\ Dosen Jurusan Karawitan Fakultas Seni Pertunjukan \\ Institut Seni Indonesia (ISI) Surakarta \\ Email: darsono@isi-ska.ac.id
}

\begin{abstract}
Abstrak
Macapat adalah salah satu karya sastra dalam bahasa daerah Jawa, Sunda, Bali dan Madura berbentuk puisi yang disusun menurut kaidah-kaidah tertentu, meliputi guru gatra, guru lagu, dan guru wilangan. Ia memiliki kandungan isi yang berbobot. Penyajiannya melalui proses penggarapan yang halus, lembut, cermat dan mantap serta senantiasa memperhatikan unsur etika dan estetika. Tembang macapat sangat populer sekitar abad XVIII dapat dikatakan menduduki puncak tangga dalam kelompok seni kraton. Tembang macapat mengandung dua unsur seni yaitu seni sastra dan seni embe/suara yang difungsikan sebagai media yang sangat komunikatif untuk menyampaikan petuah atau pesan-pesan pembangunan. Akan tetapi saat ini tinggalah catatan historis dunia sastra jawa, karena tembang macapat kini sudah tidak begitu dikenal oleh pewarisnya. Kesemuanya ini bukan disebabkan pengaruh perkembangan ilmu dan teknologi semata akan tetapi juga disebabkan kurangnya prasarana pengajaran baik berupa buku maupun pengajarnya atau kurang variatif materi tembang yang ada. Berhubungan dengan hal tersebut, sebagai karya sastra yang adiluhung menurut hemat penulis tembang macapat sangat perlu untuk dilestarikan guna memperkaya khasanah budaya Indonesia. Rencana penciptaan tembang macapat cengkok Merdi Lambang dimaksudkan sebagai wujud tindakan partisipatif dalam upaya pelestarian dan pengembangan.
\end{abstract}

Kata kunci: Tembang Macapat, berkembang, Merdi Lambang.

\begin{abstract}
Macapat is one of the literary works in the languages of Java, Sundanese, Balinese and Madurese in the form of poetry that arranged according to certain rules, including Guru Gatra, Guru Lagu, and Guru Wilangan. It has meaningful content. The presentation of Macapat is through a smooth, gentle, careful and steady cultivation process that always pays attention to ethics and aesthetics elements. Macapat song is very popular around the XVIII century. It said to occupy the top of the hits in the palace of the arts group. Macapat song contains two elements of art that are literary art and ensemble/ sound that is functioned as a very communicative media to convey development advice or messages. However at this time, Macapat remains the historical record in the world of Javanese literature because the song of Macapat now is not very well knew by its heir. All of this matter is not due to the influence of the development of science and technology itself, but it also due to the lack of teaching and supporting facilities both in the form of books and instructors or the lack of variety of existing song material. In connection to this, as a valuable literary work, the author has opinion that the song Macapat are very necessary to be preserved, in order to enrich the treasury of Indonesian culture. The plan for the creation of the Macapat tunes for Merdi Lambang are intended to be a form of participatory action for conservation and development efforts.
\end{abstract}

Keywords: Macapat Tunes, Developing, Merdi Lambang. 


\section{Pengantar}

Macapat adalah salah satu karya sastra dalam bahasa daerah Jawa, Bali dan Madura (dan juga bahasa Sasak) berbentuk puisi yang disusun menurut kaidah-kaidah tertentu, meliputi guru gatra, guru lagu, guru wilangan (Saputra, 1992:8). Macapat merupakan salah satu bentuk seni vokal (Supanggah, 1991:1). Ia memiliki kandungan isi yang berbobot. Penyajiannya melalui proses penggarapan yang halus, lembut, cermat dan mantap serta senantiasa memperhatikan unsur etika dan estetika.

Tembang macapat pada mulanya termasuk seni vokal yang bersifat mandiri (vokal murni), tidak menggunakan instrumen musik dan tangga nada dalam penyajiannya, tetapi hanya khusus vokal saja, maka hanya mengenal sistem nada yaitu slendro atau pelog. Dengan demikian tembang macapat tidak menggunakan unsur pathet dan hanya mengenal laras yaitu laras slendro atau pelog. Namun, penulisan di berbagai buku macapat biasanya selalu dicantumkan pathetnya, ini dilakukan untuk memudahkan dalam proses belajar mengajar.

Tembang macapat yang termasuk vokal murni ini, dapat hidup berdampingan dengan musik vokal dan musik instrumen murni. Kedua jenis kesenian yang dapat hidup berdampingan ini dapat dikelompokkan pada jenis kebudayaan tinggi atau "Adi Luhung" (hochkultur). (Jaap Kunst, Music in java; tone and Skill Sistem, Martinus Nijhoff, The haque, 1973, p. 11-12.

Tembang macapat pada awalnya digunakan untuk waosan atau membaca buku-buku (karya sastra) yang ditulis dalam bentuk tembang. Dimungkinkan tumbuhnya karya sastra ini dilatarbelakangi oleh tradisi oral/lisan yang cenderung menyampaikan informasi dari mulut ke mulut. Hal ini disebabkan masih banyak warga masyarakat yang belum dapat membaca dan menulis. Maka dari itu untuk menyampaikan informasi agar mudah diterima oleh masyarakat diciptakan suatu media yang menarik yaitu berupa tembang. Dalam kurun waktu sangat lama dan anggota masyarakat sudah bisa membaca dan menulis tidak mengherankan apabila tembang macapat kurang diminati oleh masyarakat. Namun demikian dengan sifat yang lentur serta menggunakan nada slendro dan pelog dalam penyajiannya, tembang macapat dapat membaur dan masuk dalam dunia karawitan dengan mengembangkan rasa musikalnya meskipun dengan bentuk dan ujud yang berbeda. Dalam dunia karawitan juga diuntungkan karena dapat menambah perbendaharaan gendhingnya.

Tembang macapat adalah salah satu jenis tembang di samping tembang gedhe, tengahan dan dolanan. Tembang macapat yang juga biasa disebut dengan tembang cilik diperkirakan sudah ada sejak jaman Majapahit, Raja Prabu Brawijaya VII tahun 1478 berkembang pada jaman Demak serta jaman selanjutnya. Penyebaran tembang ini ke wilayah timur dari Jawa (Jawa Tengah dan Jawa Timur) sampai di Bali dan ke wilayah barat sampai Sunda. Hal ini dapat dibenarkan karena hingga saat ini di Bali, Jawa dan Sunda masih terdapat tembang macapat dan masih banyak kesamaannya baik fungsi, nama tembang maupun aturannya.

Buku-buku "kuna" (serat) seperti serat "Srikandhi Meguru manah". "Centhini", "Wulangreh", "Wedhatama", "Tripama", adalah hasil karya sastra Jawa yang ditulis dalam bentuk tembang macapat. Pada cakepannya (teksnya) mengandung sanepa, paribasan, wangsalan, purwakanthi dan parikan, yang merupakan ciri sastra timur (Jawa) dan juga menunjukkan keindahan bahasa. Lebih daripada itu dongeng-dongeng, cerita-cerita, dan sejarah terdapat pula dalam tembang macapat, yang dalam hal ini merupakan bahasa baku untuk pendidikan budi pekerti dan ajaran sikap laku utama. Serat-serat semacam inilah yang biasanya dibaca dalam suatu keperluan tertentu untuk menghabiskan waktu semalam suntuk dengan berjaga (leklekan). Keperluan ini antara lain untuk upacara selapanan bayi (pada hari ke-35 sejak kelahiran bayi), khitanan, mendirikan rumah, syukuran dan nazar. Buku tersebut dibaca dengan pola macapat waosan. 
Menurut Efendy Zarkasi dalam bukunya berjudul Unsur Islam Dalam Pewayangan, penerbit PT. Alma Arif, Semarang, keberadaan macapat dikembangkan dan disempurnakan oleh para wali sebagai syi'ar agama islam. Disaat itulah para wali mencipta tembang macapat yang diantaranya:

1. Sunan Kalidjaga mencipta tembang Dhandhanggula

2. Sunan Giri Kedhaton mencipta tembang Sinom

3. Sunan Edi Eru Cakra mencipta temang Kinanthi

4. Sunan Geseng mencipta tembang Mijil

5. Sunan Murya Pada mencipta tembang Pangkur

6. Sunan Bonang mencipta tembang Durma

7. Sunan Modjo Agung mencipta tembang Maskumambang

8. Sunan Giri Prapen mencipta tembang Megatruh

9. Sunan Gunung Djati mencipta tembang Pocung

Pada Jaman Pakubuana ke X keluarga raja yang bernama KGPH Prabu Winata mencipta beberapa tembang macapat diantaranya tembang macapat Asmaradana Jakalola, Dhandanggula cengkok maskentar, Dhandhanggula Sriwandawa tetapi dikhususkan untuk Bawa lagu Laras Madya. Empu karawitan Marta Pangrawit mencipta tembang macapat dhandhanggula malatsih, sinom manungkung, kinanthi dendo khusus diperuntukan karawitan tari. Dalang terkenal Ki Narto Sabdo mencipta macapat diantaranya dhandhanggula lik suling, pangkur pelog nem, pangkur atiku lego pelog nem, Asmaradana liron sih pelog nem diperuntukan bawa gendhing ciptaanya. Sunarto Cipto Suwarso pengrawit RRI Surakarta mencipta tembang macapat Asmaradana kagok tetanon pelog nem, sinom logondang pelog lima, sinom tahu tempe pelog nem difungsikan sebagai andegan gendhing, bawa dan palaran. Sehubungan dengan hal tersebut, peneliti sebagai vokalis jawa dan pengajar tembang tergugah untuk menyipta tembang macapat waosan yang dalam hal ini diberi nama gaya atau cengkok Merdi Lambang.

Pada karya tembang macapat cengkok Merdi Lambang ada beberapa persoalan yang ada. Namun demikian peneliti membatasi diri sesuai dengan kompetensi peneliti, berdasarkan kompetensi peneliti maka persoalan tentang bagaimana tembang macapat cengkok Merdi Lambang dibuat. Dalam hal ini kreativitas seorang vokalis akan di pertanyakan dalam mencipta tembang macapat. Kreativitas disini meliputi bagaimana menyusun lagu, memisahkan antara lagu tembang laras slendro dan pelog dengan berbagai patet yang menarik untuk dihayati.

\section{Pembahasan}

Dalam penciptaan tembang macapat cengkok Merdi Lambang ini peneliti menggunakan unsur lagu yang menyajikan perbenturan harmoni adu manis, salah nggumun,kempyung, pendawan, gembyang dan tumbuk sehingga menciptakan nada-nada persial dan juga nada turunan membentuk harmoni baru yang membuat lagu tembang menjadi khas.

Tembang macapat terdiri dari rangkaian gatra atau baris, dalam penyajianya menggunakan angkatan dan seleh. Pada angkatan dan seleh inilah unsur lagu yang menyajikan perbenturan harmoni diterapkan. Lebih jelasnya lihat keterangan urutan nadanada berikut:

$$
\text { JI(1) RO(2) LU (3) MA(5) NEM(6) JI(i) }
$$

Jika gatra tembang berakhir dengan nada 1, kemudian angkatan gatra berkutnya menggunakan nada 2, maka cara seperti ini disebut dengan istilah adu manis, dari seleh 1 kemudian angkatan berikutnya menggunakan nada 3, maka hal ini disebut salah nggumun, jika seleh akhir dengan nada1, kemudian angkatan nada berikutnya dengan nada 5, maka disebut dengan istilah kempyung, apabila seleh akhir gatra menggunakan nada 1, kemudian angkatan gatra berikutnya dengan nada 6 , maka disebut pendawan, jika 
dari seleh gatra dengan nada 1,kemudian gatra berikutnya angkatan dengan nada ji atas !, maka desebut gembyang, apabila seleh gatra sebelumnya dengan nada 1 , kemudian angkatan gatra berikutnya menggunakan nada yang sama yaitu nada1, maka desebut tumbuk. Dengan demikian dapat disimpulkan bahwa dari seleh gatra menggunakan nada yang berurutan disebut adumanis, kelipatan satu nada disebut salah nggumun, kelipatan dua nada disebut kempyung, kelipatan tiga nada disebut pandawan, kelipatan empat nada disebut gembyang dan jika antara seleh akhir nada dan angkatan nada berikutnya menggunakan nada yang sama maka disebut tumbuk.

Penggunaan nada-nada dalam pembuatan lagu tembang dalam seleh akhir gatra maupun nada angkatan digatra berikutnya antara tembang berlaras slendro maupun pelog sama, menggunakan istilah yang sama, yaitu adu manis, salah gumun, kempyung, pendawan, gembyang dan tumbuk. Dalam hal ini akan lebih jelas jika kita melihat hasil karya tembang macapat cengkok Merdi Lambang pada pambicaraan berikut.

Penelitian Artistik ( Penciptaan Seni ) tentang tembang macapat cengkok Merdi Lambang ini meliputi sebelas jenis tembang macapat, dari sebelas jenis tersebut jumlah kesemuanya ada 33 pada/tembang yang dalam penyajiannya diawali dengan lagu pathetan Mijil laras slendro sebagai lagu pembuka atau pengantar. Setiap jenis tembang terdiri dari laras slendro dan pelog. yang disertai pula pathetnya. Berikut uraian dari jumlah tembang tersebut : Mijil 2 Pada, Maskumambang 2 pada, Kinanthi 4 pada, Sinom 3 pada, Durma 3 pada, Asmaradana 3 pada, Gambuh 3 pada, Dhandhang gula 3 pada, Pangkur 3 pada, Duduk Wuluh/Megatruh 3 pada dan Pocung 4 pada.

Dalam hal cakepan atau teks yang saya gunakan pada tembang cengkok Merdi Lambang ini mengambil dari serat kuna dan anggitan dari anggota paguyuban Merdi Lambang,serat tersebut yaitu serat Candrarini yasan Raden Ngabehi Ranggawarsita, Wulangreh Yasan Paku Buana IV, Serat Rama,
Langendiyan yasan RMH Tondokusuma, Serat Wedhatama yasan Mangkunegara IV, Jaka Lodhang yasan Raden Ngabehi Ranggawarsita, Gandrung kayungyun yasan RMA Wuryanungrat, Partakrama yasan Ngabehi Sindusastra, Primbon Langen Swara oleh R. NG.S. Proboharjono, Dewa Ruci oleh Pujangga Surakarta, Sabdajati yasan Raden Ngabehi Ranggawarsita dan cakepan susunan saudara Kiswaka Prono Wursita, anggota paguyuban Merdi Lambang.

\section{Analisis serta penafsiran nama tembang.}

Analisis serta penafsiran peneliti tentang nama-nama tembang macapat adalah gambaran perjalanan hidup manusia sejak lahir sampai meninggal dunia . Dari kesebelas jumlah tembang macapat yang telah disebut diatas terdapat tiga tembang Tengahan ( Balabak, Wirangrong, Juru Demung) dan satu tembang Gedhe(Girisa) yang mengelompok kedalam tembang macapat. Keempat tembang tersebut mengelompok kedalam tembang macapat karena mempunyai lagu yang sederhana/lugu yang menyerupai tembang macapat. Akan tetapi disamping mempunyai kemiripan dalam hal rasa musical, nama tembang tersebut erat hubungannya dengan analisis serta penafsiran tentang nama tembang.

Berikut urutan nama-nama tembang tersebut:

1. Mijil

2. Maskumambang

3. Kinanthi

4. Sinom

5. Durma

6. Asmaradana

7. Gambuh

8. Dhandhang Gula

9. Pangkur

10. Megatruh/Duduk Wuluh

11. Pocung

12. Balabak

13. Wirangrong

14. Juru Demung

15. Girisa. 
Mijil, dalam bahasa jawa mempunyai pengertian yang sama dengan kata miyos,metu dan lahir , melambangkan kelahiran seorang bayi dari guwa garba (rahim) sang ibu kealam yang baru yaitu didunia ini. Kata baru disini mengandung pengertian belum pernah dikenal sebelumnya, sehubungan dengan itu seseorang yang masuk kewilayah lain dengan aturan serta budaya yang lain pula dan serba baru, maka dalam hal ini juga bisa disebut Mijil seperti halnya bayi tersebut.

Maskumambang, Mas adalah perhiasan yang mahal harganya, kumambang adalah suatu benda berada diatas air/ kemampul, oleh sebab itu jika terkena hempasan angin / udara, maka akan bergeser kesana kemari sesuai dengan arah angin tersebut, itulah gambaran seorang anak yang masih bayi, selain itu bayi bagaikan kertas yang masih putih, ditulisi dengan tinta merah maka hasil tulisannya juga berwarna merah, ditulisi dengan tinta biru maka hasil tulisannya berwarna biru, hal ini sebagai perhatian pada orang tua agar mendidik anak mulai kecil/bayi harus benar dan tepat.

Kinanthi, berasal dari kata kanthi yang berarti gandheng atau digandheng. Anak berumur satu hingga satu setengah tahun biasanya mulai dilatih berjalan digandheng, ditetah, dikanthi setapak demi setapak dengan sabar sang ibu melakukan menganthi kesana kemari. Menganthi latihan berjalan oleh sang ibu terhadap anak ini sang ibu menuntun pula dengan berbagai ucapan untuk ditirukan misalnya Bapak, Ibu, kakak, Simbah, maem, mik dan sebagainya. Apabila si anak sudah berumur 7 tahun orang tua seharusnya sudah memulai memantau bakat anak, Sehubungan dengan penentuan bakat anak maka kita perhatikan dalam lagu dolanan Jamuran berikut:

Jamuran ya gege thok, jamur apa ya gege thok jamur gajih mberjijih sa ara-ara.

Jamururan, Datangnya masa, sebagai perumpamaan anak dari lahir hingga dewasa,yang mengalami beberapa masa, yaitu meliputi masa kemrusuh, ke mratu-mratu, dumolan, birahi dan sebagainya.
Ya Ge ge thok, disetiap pergantian masa orang tua harus waspada, jika sudah terlihat bakat si anak cepat-cepat di thok/ditentukan.

Jamur apa, apa yang menjadi bakat anak tersebut.

$Y a$, jika sudah dimengerti bakatnya orang tua hanya bilang Ya,tidak dibenarkan jika diarahkan yang bukan bakatnya.

Jamur gajeh, apabila sudah jelas maka akan tumbuh jamur gajeh

Mbegigeh, adalah suara kuda,ada yang mengatakan tertawa

Sa ara ara, berkembang pesat.

Sinom, kata sinom diartikan daun muda , anom,enom, atau pupus melambangkan seorang anak mulai berkembang bagaikan daun yang bersemi, yang termasuk dalam anak muda ini diperkirakan anak sekolah menengah tingkat pertama(SLTP) dan anak sekolah tingkat menengah atas (SLTA). Anak seusia ini mempunyai karakter yang keras, segala sesuatu yang dikehendaki harus terlaksana, oleh sebab itu orang tua harus sangat peduli dan membina agar anak menjadi baik serta menurut nasehat orang tua. Dalam ajaran kuna pertanggung jawaban terhadap anak itu seperti yang tertera dalam lagu SlukuSluku bathok. Berikut lagu tersebut, Sluku-Sluku bathok, bathoke e la e lo, si Rama menyang kutha leh olehe payung motha, pak jenthit lo lo lo bang lambok ijo lombok abang.

Sluku-Sluku bathok, bathoke e la elo: yang dimaksud adalah kuwajiban orang tua menjaga anak.

Si Rama menyang kutha leh olehe payung motha: orang tua sampai kapan pun tetap berkuwajiban Mayungi/menjaga anak.

Mak jentit lo lo lo bang: apabila anak putri sudah datang bulan, dan atau anak laki-laki sudah bermimpi basah,

Lombok ijo Lombok abang: menjaganya harus lebih cermat dan tepat.

Durma: Kata Durma mengandung pengertian Sima atau Harimau, yang mempunyai watak kasar dan bengis serta bernuansa keras, karena hewan tersebut pemangsa daging. Sebagai orang tua harus 
memahami dan sangat peduli terhadap putraputrinya yang masih remaja. Pada tayangan Televisi maupun dimuat surat kabar sering terjadi tawuran anak sekolah seuaia SLTP maupun SLTA yang mengakibatkan cidera di kedua belah pihak, bahkan ada yang sampai meninggal dunia.

Asmaradana: Kata Asmaradana terdiri dari kata asmara dan dana. Kata asmara berarti jatuh cinta dan kata dana mempunyai pengertian yang sama dengan kata dahana yang dimaksud adalah api, jadi kata asmaradana itu diartika asmara yang berapiapi alias jatuh cinta. Diperkirakan anak yang sudah dewasa, sudah kuliah di bangku perguruai tinggi, mulai mengenal teman lawan jenisnya, misalnya anak perempuan berkata: wah temanku si Bambang itu orangnya cakep, badannya atletis jika berpakaian necis dan ramah juga. Sebaliknya si priya berkata:Wah dik Endang itu orangnya cantik, pandai bergaul, buah dadanya montok, kulitnya halus jikaberbicara kalem dan bikin gemes saja, apa lagi jika mengenakan baju batik, wah bikin pusing aja. Dimasa inilah remaja muda ini sudah berpacaran, yaitu saling mengenal karakter satu sama lainnya, makan bersama, naik kendaraan berdua, setiap malam minggu si priya apel/datang kerumah si wanita untk sekedar bertemu tapi juga memperkenalkan pada orang tua si wanita.

Gambuh: Kata gambuh mepunyai pengertian dengan kata Jumbuh atau cocok. Setelah kedua remaja laki perempuan berpacaran yang cukup lama ,sudah saling mengerti atau memahami karakter satu sama lainnya, sudah sama-sama lulus kuliah bahkan sudan bekerja serta kedua orang tua sudah merestui hubungan berdua, maka direncanakan untuk melangsungkan pernikahan.

Dhandhang Gula: Istilah Dhandhang Gula berasal dari kata dhandhang dan gula. Kata dhandhang mempunyai pengertian burung gagak, alat untuk menyungkal,sangat jelas dan mengharap supaya.... Dari keempat pengertian tersebut sepertinya mengharap supaya.... paling tepat untuk memaknai kata dhandhang. Sedangkan kata gula berarti manis, menyenangkan dan baik.
Tembang Dhandhang Gula ini melukiskan manis-manising ngaurip, menyenangkan dan segala sesuatu bejalan dengan baik,atau puncaknya manusia hidup yaitu saat melangsungkan pernikahan. Pada waktu perhelatan berlangsung segala keperluan kedua mempelai dicukupi dengan berbusana yang khusus dan mahal harganya serta disaksikan sanak saudara, teman bekerja, para pejabat dan makan maupun minum ada pegawai khuaus yang melayaninya, maka dari itu juga disebut dengan istilah Raja Sehari dengan pengertian seperti seorang raja yang segala sesuatunya selalu dilayani dan dicukupi. Didalam menjalani kehidupan berumah tangga ini mempelai berdua tentu saja bergaul dengan masyarakat yang homogin, sehubungan dengan itu sangat relevan jika dapat memaknai isi dari lagu dolanan menthok-menthok berikut ini.

Kata si Jago kepada menthok: Menthokmenthok tak kandani,mung solahmu, angisin isini mbok ya aja ngetok ana kandhang wae enak -enak ngorok ora nyambut gawe, menthok-menthok mung lakumu megal megol gawe guyu.

Kata-kata itulah setiap saat dilontarkan si Jago kepada Menthok, Si Menthok diam seribu bahasa, ia menyadari memang beginilah aku ditakdirkan hidup. Cemohoan si Jago itu tiada henti,maka suatu saat hilang kesabaran si Menthok dan membalas dengan kata-kata sebagai berikut: Jago-Jago soto loyo, kowe pinter nanging bodho apa kowe wani, wani karo aku ayo padha mlaku ana duwur banyu, Jago-Jago aja mlongo kowe pinter nanging bego. Mendengar kemarahan si menthok dengan kata-kata seperti itu, Jago mengaku salah dan meminta maaf, Jago menyadari jika tidak bisa berenang. Dari tembang tersebut dapat diambil hikmahnya bahwa dalam pergaulan di masyarakat atau hidup bermasyarakat terdiri dari beberapa orang yang berbeda latarbelakangnya serta berbeda pula kemampuannya, ada yang kaya ada yang miskin, ada pejabat ada rakyat biasa, oleh karena itu perbedaan serta kemampuan justru saling mengisi saling bekerja sama sehingga dapat mewujudkan hidup rukun dilingkunganya. 
Pangkur: Kata Pangkur berasal dari akar kata Kur yang mempunyai pengertian "belakang" . Adalah Hardjowirogo memberi arti kata pangkur sama dengan kata buntut atau ekor. Ekor merupakan bagian belakang termasuk ujung belakang hewan.Makna ujung dapat juga mengacu pada puncak. Disamping itu orang jawa mengartikan kata pangkur sama dengan kata mungkur dengan maksud bahwa seseorang dalam hidupnya sudah membelakangi dan meninggalkan kesenangan dunia. Didalam lagu dolanan dalam hal membelakangi dunia ini seperti yang terurai dalam lagu dolanan Blak Cublak suweng, berikut penjelasannya:

Blak cublak suweng, suwenge ting gelenter, mambu ketundung gudel,pak kampong lera lere,sapa ngguyu ndelikake, sir sir pong dele gosong, sir sir pong dele gosong.

Cublak- cublak suweng: Cublak berarti tetap. Yang dimaksud adalah duduk dengan sikap semedi, mengosongkan panca indra, nutupi babahan hawa sanga / menutp semua lubang yang terdapat pada diri seseorang, ana rasa tan rinasa , ana ganda tan ginanda, (ada rasa tidak dirasakan, ada bau tidak dinikmati, keadaan seperti ini bagaikan meninggal dalam kehidupan.( mati sajroning urip).

Suwenge ting gelenter: Keluar masuknya napas tertata dengan baik (nggelenter).

Mambu ketundung gudel: Disini sudah ada tanda aroma yang harum yang mengusir aroma yang tidak sedap. ( ketundung gudel= aroma tidak sedap).

Pak kempong lera lere yang dimaksud pak= ngempakke

Sapa ngguyu ndelikake: Tertawa didalam hati kesemuanya sudah terselesaikan.

Sir pong: Seseorang yang sudah terbiasa melakukan laku prihatin atau mengosongkan diri/ sudah kopong, biasanya sudah tidak memikirkan kebahagiaan dunia.

Dele Gosong: Dikarenakan sudah tidak memikirkan kebahagiaan dunia, maka keindahan jasmanipun tidakdiperhatikan maka seperti halnya kedelai yang terbakar / gosong berwarna hitam kusem dan tidak menarik,akan tetepi jika dikupas keelai tersebut terlihat kuning bersinar jika dimakan terasa enak dan gurih.
Megatruh, berasal dari kata Megat dan Ruh , Megat berarti pisah sedangkan ruh berarti jiwa, jadi Megatruh bermakna meninggal dunia, tembang ini melambangkan bahwa manusia sudah usai melaksanakan tugas-tugas di dunia dan kembali kealam baka. (pulang ke jaman kelanggengan).

Pocung, yaitu buah keluak. Pocung disamakan dengan kata pocong, aturan didalam Agama Islam orang yang telah meninggal dunia sebelum dimakamkan atau dikubur,terlebih dahulu dimandikan kemudian dipocong dengan kain kafan yang berwarna putih.

Balabak, setelah dipocong dengan kain kafan warna putih, mayat dimasukkan ke Bandosa, yaitu tempat mayat yang terbuat dari kayu atau ada yang menyebut Blabak.

Wirangrong, kata ini berasal dari akar kata rong yang berarti lubang,sedangkan kata wirang berarti malu. Dipercaya oleh sebagian masyarakat jika seseorang yang meninggal dunia dan orang tersebut disaat hidupnya punya kelakuan yang tidak terpuji, misalnya punya pesugihan, seorang preman,sering membunuh orang, maka saat akan dikubur sering terjadi sesuatu yang bikin malu karena ada keanehan. Proses pemakaman mayat jika sudah didoakan oleh seorang modin kemudian dimasukkan keliang lahat atau rong.

Juru Demung, Juru berarti tukang sedangkan demung adalah instrument gamelan jawa yang besar, kuat dan tebal, maka dari itu penabuhnya dipilih pengrawit yang rosa (kuat) untuk memukul instrument tersebut. Didalam alam kubur kata Ustad orang yang baru saja meninggal akan ditanya oleh Malaikat, yaitu Agamamu apa?, Nabimu siapa/ Kitabmu apa? Jika tidak bisa menjawab maka oleh Malaikat akan dihajar dan pukul dengan sangat keras seperti halnya pemukul demung.

Girisa, Informasi tentang alam kubur dan orang yang sedang meninggal dihajar oleh Malaikat karena tidak bisa menjawab pertanyaan itu membuat hati, giris dan miris . Dalam hal ini ditengarai dengan tembang Gedhe Girisa. 
Tembang macapat juga dikenal dengan tembang alit adalah gambaran rakyat kecl, tembang tengahan adalah gambaran orang kelas menengah, sedangkan tembang gedhe gambaran orang besar, orang berpangkat, orang punya jabatan tinggi, akan tetapi dalam alam kubur mengalami hal yang sama. Didalam tembang Maskumambang karya Wali Sanga menyebutkan tentang alam kubur tersebut. Berikut syairnya, Kelek-kelek biyung sira aneng ngendi, babo tulungana, awakku kecemplumg warih, gulagepan wus meh pejah. Pada suatu saat salah satu induk ayam(Babon) bersama beberapa kuthuknya mencari makan ditanah lapang, tiba-tiba salah satu kuthuknya diambil burung elang dibawa terbang, namun kurang kuat cengkeramannya si kuthuk lepas dan jatuh digenangan air atau diparit,, si kuthuk menangis minta tolong memanggil ibunya, babon datang beserta kuthuk yang lain ,mereka bisa berdekatan namun tidak bisa menolong. Gambaran dalam tembang Maskumambang tersebut jelas bahwa dialam kubur tidak ada yang bisa menolong saat ditanya Malaikat dan tidak bisa menjawab dengan benar. Sebagai contoh tembang Macapat Cengkok Merdi Lambang yang peneliti buat yaitu sebagai berikut:

\section{Mijil, Laras Pelog Nem}

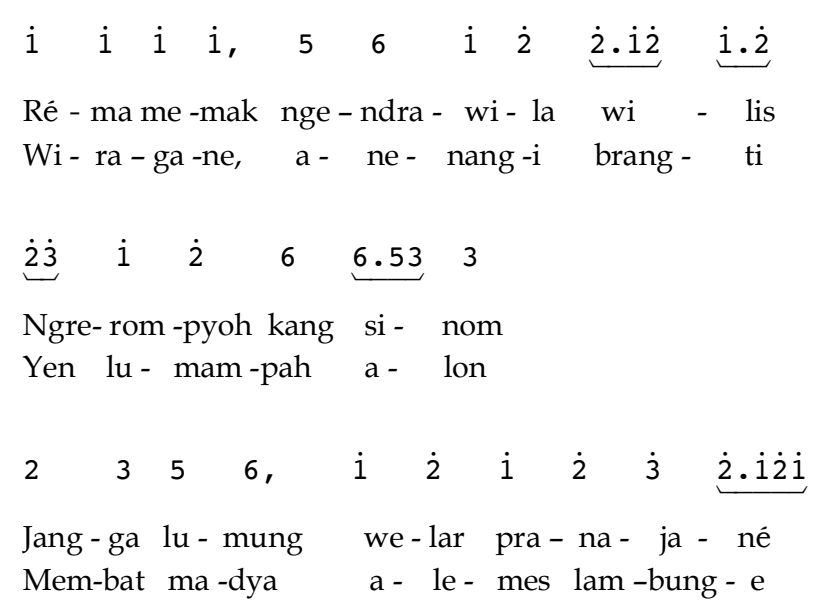

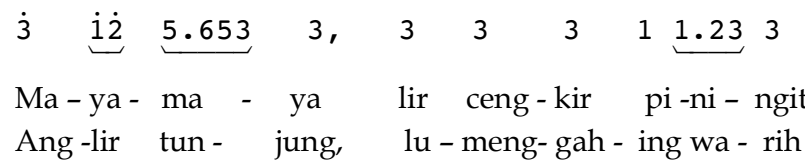

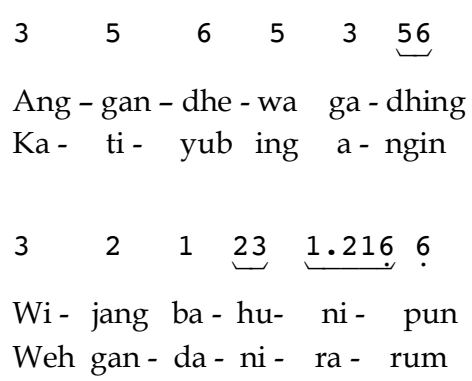

(Serat Candrarini- Raden Ngabehi Ranggawarsita)

Tembang macapat Mijil peneliti susun pada tanggal 07- Juni- 2012, pada saat itu setelah sholat Subuh saya duduk di emperan rumah dan melagukan lagu tembang macapat, namun tidak jelas jenis macapatnya. Hal tersebut saya ulang beberapa kali yang akhirnya kucoba dengan cakepan mijil, jadilah satu pada tembang mijil slendro,setelah itu kucoba melagukan yang lain dengan laras pelog, tersusunlah tembang macapat mijil laras pelog.

\section{Maskumambang, Laras Pelog Nem}

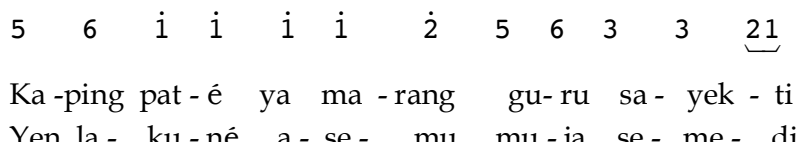

$\dot{3} \underbrace{i \dot{2}} \quad 6 \quad 5 \quad \underbrace{6.53} 3$

Sembah ka-ping li-ma

A -nglung - guh - i ke-blat

$\begin{array}{lllllllll}3 & 3 & 3 & 3 & 2 & \underbrace{33} & \underbrace{12} & 2\end{array}$

Ya ma - rang Gus - ti - ni - rè - ki

Te - ges - é wus no -ra ging -sir

$\begin{array}{llllllll}2 & 3 & 5 & 6 & 5 & 4 & 4.565 & 5\end{array}$

Pa - rin - cè né ka-wruh - a - na

Ka - ta - man keh -ing ru - be - da

(Serat Wulangreh yasan Paku Buwana IV)

Sekar macapat Maskumambang saya susun pada tanggal 19 Mei 2013. Pada saat itu saya berpikir tentang macapat 
Maskumambang yang dikenal masyarakat pasti berlaras pelog, maka saya mencoba menyusun yang lain yaitu Maskumambang laras slendro. Dengan berbagai menata nada dan berulang kali melagukan macapat dengan ciri struktur Maskumambang maka terbentuklah lagu Maskumambang baru laras slendro miring. Setelah itu saya susun tembang macapat Maskumambang laras pelog pathet nem.

\section{Kepustakaan}

Rochkyatno, Amir. 1998. Tembang Macapat Yang Tersurat Dan Tersirat Dalam Menanggapi Perkembangan Sosial. Fakultas Sastra UGM, Yogyakarta.

Suryadi, Linus A. G. 1995. Dari Pujangga ke Penulis Jawa, Alex Sadewa, Penerbit Pustaka Pelajar, Yogyakarta.

Sukmono, R . 1973. Pengantar Kebudayaan, Jilid I.

Soedarsono. 1995. Pengantar Sejarah Kesenian I, bahan kuliah, , UGM, Yogyakarta.

Soegito. 1996. Seni Suara Daerah, Muatan Lokal Kabupaten Wonogiri.

Endraswara, Suwardi .1995. Mulang Kopetensi Macapat, Bengkel Sastra Jawa Balai Bahasa Yogyakarta.

Kayam, Umar.1973. “Apakah seni perlu dibina" dalam seni jurnal pengetahuan dan penciptaan seni, III/03, Juli,
Mardimin, Yohanes Sekitar tembang macapat, penerbit satya wacana

Yudayana, Bambang. 1984. Gamelan Jawa", Awal Mula-makna Masa depannya, Penerbit PT. Karya Unipress, Jakarta,

Benard Arps. 1989. “Antara Nembang dan Maca, Dampak Ilmu Pengetahuan dan Teknologi Modern," pada pembacaan puisi jawa tradisional di Yogyakarta.

Jumiran, R. A. Al. 1996. Inovasi Tembang Jawa, Konggres Bahasa Jawa II Batu, Malang.

CF. Winter SR. 1880. Serat Bausastra Jawa Kawi, 1880, Betawi: Cap-Capan Gupermen.

Darsono dkk. 1992. Tembang Jawi, Penerbit Dita Nugraha Surakarta Marwanto Tuntunan Sekar Macapat. Penerbit Tiga Serangkai, Surakarta.

Zarkasi, Efendy Unsur Islam Dalam Pewayangan, Penerbit PT. Alma Arif, Semarang, t.t.:149

Hascaryo, Gunawan Sri Macapat I,II,III

Kunst, Jaap. 1973. Music in java; tone and skill system, Martinus Nijhoff, The haque.

Sindoesawarno, Ki'Ilmu Karawitan" Konservatori Karawitan Indonesia, Surakarta, t.t. 